\title{
Biotransformation of Isoflavones by the Larvae of the Common Cutworm (Spodoptera litura)
}

\author{
Koji Takahashi, ${ }^{a}$ Hideo Araki, ${ }^{b}$ and Mitsuo MiYazawa ${ }^{*}, a$ \\ ${ }^{a}$ Department of Applied Chemistry, Faculty of Science and Engineering, Kinki University; Kowakae, Higashiosaka, Osaka \\ 577-8502, Japan: and ${ }^{b}$ Fuji Oil Co., Ltd. Hannan R\&D Center; 1 Sumiyoshi-cho, Izumisano, Osaka 598-8540, Japan. \\ Received November 10, 2005; accepted January 24, 2006; published online February 6, 2006
}

Biotransformation of the 5,7,4'-trimethoxyisoflavone (1), 6,7,4'-trimethoxyisoflavone (2), and 7,4'-dimethoxyisoflavone (3) by insects, Spodoptera litura was investigated. Compound 1 was transformed to 5-hydroxy7,4'-dimethoxyisoflavone (4), 7-hydroxy-5,4'-dimethoxyisoflavone (5) and 4'-hydroxy-5,7-dimethoxyisoflavone (6) by $S$. litura. Compounds 2 and 3 were hardly metabolized by $S$. litura. This suggested that compound 1 was converted to compounds 4,5 and 6 by demethylation at the C-5, C-7 and C-4' position, respectively.

Key words biotransformation; isoflavone; Spodoptera litura; biocatalyst; demethylation

The naturally occurring isoflavones are reported to possess diverse biological activities, including antioxidative, ${ }^{1)}$ antifungal $^{2)}$ and estrogenic ${ }^{3,4)}$ activity. Recently, an osteoporosis preventive effect ${ }^{5)}$ and mitigation of menopausal disorders ${ }^{6}$ ) has attracted attention and various physiological activities of isoflavone are expected. It has been reported that these activities were enhanced in the biotransformation. ${ }^{7,8)}$ Biotransformation possesses the advantage of proceeding under mild conditions and with high regio- and enantioselectivity. Esaki et al. reported the biotransformation of soybean isoflavones to 8-hydroxydaidzein and 8-hydroxygenistein by Aspergillus satoi and these isoflavones exhibited significantly stronger antioxidative activity than daidzein and genistein. ${ }^{7)}$ Therefore, it is important to produce the bioactive isoflavone derivatives and to elucidate their metabolic pathways in microorganisms and insects.

In the course of our work, we have studied the biotransformation of isoflavonoids and terpenoids by fungi and insects as a biocatalyst. ${ }^{9-14)}$ In a previous paper, we reported the biotransformation of the isoflavones, 7, $4^{\prime}$-dimethoxyisoflavone and 7,4'-diacetoxyisoflavone, by Aspergillus niger. 7,4'-Dimethoxyisoflavone was transformed to 6-hydroxy-7,4'-dimethoxyisoflavone and daidzein, while 7,4'-diacetoxyisoflavone was also transformed to daidzein by hydrolysis. ${ }^{10)}$ In this paper, we report the synthesis of isoflavones, 5,7,4' ${ }^{\prime}$-trimethoxyisoflavone (1), 6,7,4' -trimethoxyisoflavone (2) and 7,4'-dimethoxyisoflavone (3) and the biotransformation of compounds $\mathbf{1}, \mathbf{2}$ and $\mathbf{3}$ by insect, Spodoptera litura.

\section{Results and Discussion}

Compound 1 was metabolized by $S$. litura. Compounds 2 and 3 were hardly metabolized by $S$. litura.

The transformation of 5,7,4'-trimethoxyisoflavone (1) by $S$. litura was examined. Extracts were chromatographed on silica gel column chromatography to give metabolites. Metabolites 4 (6 mg), $5(5 \mathrm{mg}), 6(3 \mathrm{mg})$ and substrate 1 $(130 \mathrm{mg})$ were isolated. In order to determination of structure of the metabolites, metabolites $\mathbf{5}$ and $\mathbf{6}$ were acetylated.

Metabolites 4, 5 and 6 showed the molecular formula of $\mathrm{C}_{17} \mathrm{H}_{14} \mathrm{O}_{5}$ in their HR-EI-MS, respectively. The ${ }^{1} \mathrm{H}-\mathrm{NMR}$ spectrum of compounds $\mathbf{4 , 5}$ and $\mathbf{6}$ showed the presence of two methoxyl groups, which indicated that one methoxy sig- nal has disappeared compared with compound 1. Furthermore, compound 4 had a signal of hydrogen bond at $\delta 12.85$. Compounds 5 and $\mathbf{6}$ were converted monoacetyl compounds, 5Ac and 6Ac by reaction with acetylation. It results that compounds 4, 5 and $\mathbf{6}$ showed the presence of two methoxyl groups and one hydroxy group, respectively (see Table 1).

Compounds $\mathbf{4}$ and $\mathbf{5}$ also showed a significant mass fragment at $\mathrm{m} / \mathrm{z} 166$ and 132, and compound $\mathbf{6}$ also showed a significant mass fragment at $m / z 180$ and 118, respectively. In a previous article, Talukdar et al. reported the structure of 5hydroxy-7,4'-dimethoxyisoflavone by the retro Diels-Alder fragments at 166 and 132 formed after the retro Diels-Alder reaction indicating the presence of one methoxyl and one hydroxy groups in ring $\mathrm{A}$, and one methoxy group should be present in ring $\mathrm{B}^{15)}$ In the identification of the isoflavones, the retro Diels-Alder fragmentation was found to be important. ${ }^{16,17)}$

In our previous paper, we reported the biotransformation of sinesetin by larvae of $S$. litura. The main pathway was demethylation at C-6 position followed by glucosylation, and the minor pathway was demathylation at the $\mathrm{C}-4^{\prime}$ position. ${ }^{13}$ )

These results showed that compound $\mathbf{4}$ had the hydroxy group at C-5 position and compound $\mathbf{5}$ had the hydroxy group at C-7 position. Compound $\mathbf{6}$ also showed a significant mass fragment at $\mathrm{m} / \mathrm{z} 180$ and 118 formed after the retro Diels-Alder reaction indicating the presence of two methoxyl groups in ring $\mathrm{A}$, and one hydroxy group should be present in ring B. Thus from compound $\mathbf{6}$ had the hydroxy group at C-4' position.

Thus from the foregoing spectral studies the structure of compounds 4, 5 and 6 were identified as 5-hydroxy-7, $4^{\prime}$ dimethoxyisoflavone, 7-hydroxy-5,4'-dimethoxyisoflavone and 4 '-hydroxy-5,7-dimethoxyisoflavone, respectively. Spectral data of compound $\mathbf{4}$ were assigned by comparison with the previous paper. ${ }^{15)}$ Compound $\mathbf{5}$ was obtained by synthesis

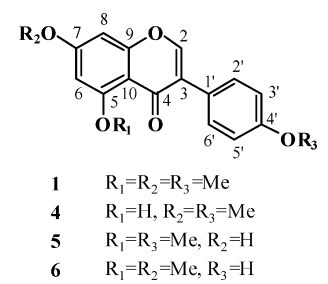


from the chalcone. ${ }^{18)}$ In our previous paper, compound 6 was obtained by microbial transformation. ${ }^{17)}$ The ${ }^{1} \mathrm{H}-\mathrm{NMR}$ spectrum analysis of compounds 5Ac and 6Ac were not reported, and thus this is the first report of the ${ }^{1} \mathrm{H}-\mathrm{NMR}$ spectrum analysis of compounds 5Ac and 6Ac.

Compound $\mathbf{1}$ was transformed to compounds $\mathbf{4 , 5}$ and $\mathbf{6}$. Metabolites 4, 5 and $\mathbf{6}$ were compounds in the demethylation of compound 1 at the C-5 and C-7 and C-4' position, respectvely. On the other hand, compounds $\mathbf{2}$ and $\mathbf{3}$ were not converted. These results indicate that compound $\mathbf{1}$ showed substrate specificity for this biotransformation. This is the first report of biotransformation of 5,7,4'-trimethoxyisoflavone (1) by $S$. litura. It is interesting to note that demethylation of one position are easily obtained by insects.

\section{Experimental}

General Procedure Nuclear magnetic resonance (NMR) spectra were obtained with a JEOL FX-500 $\left(500.00 \mathrm{MHz},{ }^{1} \mathrm{H} ; 125.65 \mathrm{MHz},{ }^{13} \mathrm{C}\right) \mathrm{spec}-$ trometer. Tetramethylsilane (TMS) was used as the internal standard $(\delta$ $0.00)$. IR spectra were determined with a JASCO FT/IR-470 plus Fourier transform infrared spectrometer. EI-MS spectra were obtained on a JEOL the Tandem MS station JMS-700 TKM. Gas chromatograph (GC) was performed on a Hewlett-Packard 5890 gas chromatograph equipped with a flame ionization detector (FID). GC-MS was performed on a HewlettPackard 5972 series mass spectrometer interfaced with a Hewlett-Packard 5890 gas chromatograph fitted with a column (HP-5MS, $30 \mathrm{~m}$ length, $0.25 \mathrm{~mm}$ i.d.)

Preparation of Isoflavones Genistein, glycitein and daidzein were isolated soyaflabon HG (powder of Glycine max, purchased from FUJI Oil Co., Ltd. (Osaka, Japan).

Synthesis of Substrates Methylation of isoflavones were carried out according to the synthetic method of Matsuda et al. ${ }^{19)} \mathrm{A}$ solution of genistein $(200 \mathrm{mg}$ ) in $\mathrm{N}, \mathrm{N}$-dimethylformamide (DMF, $12 \mathrm{ml}$ ) was treated with methyl iodide $\left(\mathrm{CH}_{3} \mathrm{I}, 0.6 \mathrm{ml}\right)$ in the presence of sodium hydride $(\mathrm{NaH}, 60 \mathrm{mg})$ and the mixture was stirred at room temperature for $12 \mathrm{~h}$. 5,7,4'-Trimethoxyisoflavone (1) $(180 \mathrm{mg})$ was obtained. Through a similar procedure of methylation, 6,7,4'-trimethoxyisoflavone (2) $(188 \mathrm{mg})$ was obtained from

Table 1. ${ }^{1} \mathrm{H}-\mathrm{NMR}$ Spectral Data of Compounds 1, 4, 5Ac and 6Ac

\begin{tabular}{lllll}
\hline \hline No. & \multicolumn{1}{c}{$\mathbf{1}$} & \multicolumn{1}{c}{$\mathbf{4}$} & \multicolumn{1}{c}{$\mathbf{5 A c}$} & \multicolumn{1}{c}{ 6Ac } \\
\hline 2 & $7.76 \mathrm{~s}$ & $7.86 \mathrm{~s}$ & $7.82 \mathrm{~s}$ & $7.79 \mathrm{~s}$ \\
6 & $6.36 \mathrm{~d}(2.3)$ & $6.40 \mathrm{~d}(2.4)$ & $6.58 \mathrm{~d}(2.5)$ & $6.38 \mathrm{~d}(2.3)$ \\
8 & $6.44 \mathrm{~d}(2.3)$ & $6.38 \mathrm{~d}(2.4)$ & $6.85 \mathrm{~d}(2.5)$ & $6.46 \mathrm{~d}(2.3)$ \\
$2^{\prime}, 6^{\prime}$ & $7.47 \mathrm{dt}(8.9,2.0)$ & $7.45 \mathrm{dt}(8.9,2.4)$ & $7.48 \mathrm{dt}(8.4,1.9)$ & $7.56 \mathrm{dt}(8.4,2.0)$ \\
$3^{\prime}, 5^{\prime}$ & $6.93 \mathrm{dt}(8.9,2.0)$ & $6.98 \mathrm{dt}(8.9,2.4)$ & $6.94 \mathrm{dt}(8.4,1.9)$ & $7.13 \mathrm{dt}(8.4,2.0)$ \\
$\mathrm{OMe}$ & $3.93 \mathrm{~s}$ & $3.87 \mathrm{~s}$ & $3.96 \mathrm{~s}$ & $3.94 \mathrm{~s}$ \\
& $3.88 \mathrm{~s}$ & $3.84 \mathrm{~s}$ & $3.84 \mathrm{~s}$ & $3.90 \mathrm{~s}$ \\
& $3.82 \mathrm{~s}$ & & & $2.31 \mathrm{~s}$ \\
$\mathrm{OAc}$ & & & $2.35 \mathrm{~s}$ & \\
$\mathrm{OH}$ & & $12.85 \mathrm{~s}$ & & \\
\hline
\end{tabular}

${ }^{1} \mathrm{H}-\mathrm{NMR}$ recorded at $500.0 \mathrm{MHz}$ in $\mathrm{CDCl}_{3}$, TMS as internal standard.

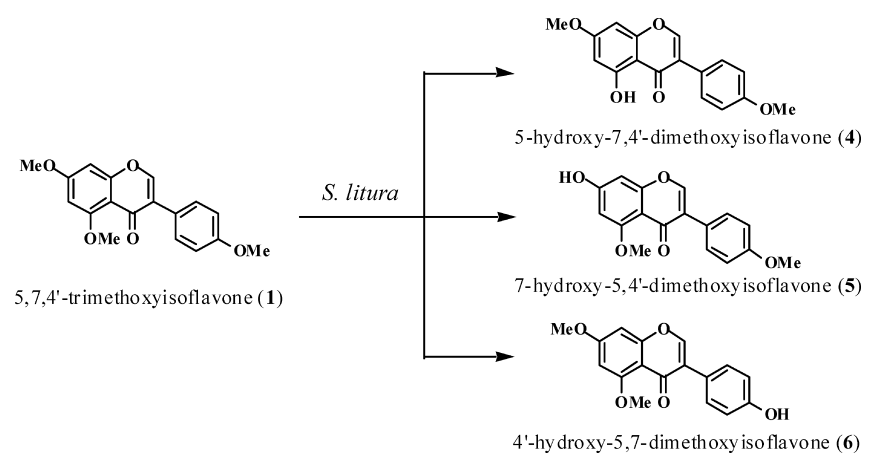

Chart 1. Biotransformation of compound $\mathbf{1}$ by $S$. litura glycitein and 7,4'-dimethoxyisoflavone (3) $(190 \mathrm{mg})$ was obtained from daidzein. These spectral data were assigned by comparison with the previous paper. $^{10,17)}$

Rearring of Larvae The larvae of $S$. litura were reared in plasticcases $(200 \times 300$ wide, $100 \mathrm{~mm}$ high, 100 larvae/case) covered with a nylon mesh screen. The rearing conditions were as follows: $25^{\circ} \mathrm{C}, 70 \%$ relative humidity, and constant light. A commercial diet (Insecta LF; Nihon Nosan kogyo Co., Ltd.) was given to the larvae from the first to sixth (last) instar.

Administration of 5,7,4' -Trimethoxyisoflavone (1) The diet of 100 larvae (fourth-fifth instar) was changed to an artificial diet composed of kidney beans $(100 \mathrm{~g})$, agar $(12 \mathrm{~g})$, and water $(600 \mathrm{ml})$. After $1 \mathrm{~d}$, the artificial diet without the agar was mixed with a blender. Compound $\mathbf{1}(150 \mathrm{mg})$ was then added to the blender at $1 \mathrm{mg} / \mathrm{g}$ of diet. Ager was dissolved in water and boiled and then added to the blender. The diet was then mixed and cooled in a tray. The larvae were moved into new cases, and the diet containing compound 1 ( $3 \mathrm{mg}$ for a body) were fed for $2 \mathrm{~d}$, and then the artificial diet not containing compound 1 was fed to the larvae for an additional $2 \mathrm{~d}$. Frass was collected daily and stored in a solution of $\mathrm{CHCl}_{3}(100 \mathrm{ml})$.

The frass was extracted with $\mathrm{CHCl}_{3}(100 \mathrm{ml} \times 3)$ and EtOAc $(100 \mathrm{ml} \times 2)$. These extracts were mixed, the solvent was evaporated under reduced pressure, and $211.9 \mathrm{mg}$ of extract was obtained. The extract was analyzed by TLC and GC-MS; metabolites $\mathbf{4 , 5}$ and $\mathbf{6}$ occurred in this extract. The extract was fractionated by $\mathrm{SiO}_{2}$ column chromatography with $\mathrm{CH}_{2} \mathrm{Cl}_{2}$ /acetone as eluents. Recovery substrate $\mathbf{1}(130 \mathrm{mg})$ was isolated. Three metabolites 4 $(6 \mathrm{mg}), 5(5 \mathrm{mg})$ and $\mathbf{6}(3 \mathrm{mg})$ were isolated. The acetylated derivatives of compounds $5(5 \mathrm{Ac})$ and $6(6 \mathrm{Ac})$ were obtained by reaction with $\mathrm{Ac}_{2} \mathrm{O}$ and pyridine.

5-Hydroxy-7,4'-dimethoxyisoflavone (4): White crystals, HR-EI-MS, $m / z$ $298.0833[\mathrm{M}]^{+}$, Calcd for $\mathrm{C}_{17} \mathrm{H}_{14} \mathrm{O}_{5}, 298.0842$; EI-MS, $m / z$ (\%) (rel. int.) $298[\mathrm{M}]^{+}$(100), 297 (13), 283 (10), 255 (4), 166 (12), 149 (7), 132 (17), 117 (5); IR ( $\mathrm{KBr}) v_{\max } \mathrm{cm}^{-1} 1614,1576,1515,1441 ;{ }^{1} \mathrm{H}-\mathrm{NMR}\left(\mathrm{CDCl}_{3}\right)$ see Table 1.

7-Hydroxy-5,4'-dimethoxyisoflavone (5): White crystals, HR-EI-MS, $m / z$ $298.0860[\mathrm{M}]^{+}$, Calcd for $\mathrm{C}_{17} \mathrm{H}_{14} \mathrm{O}_{5}, 298.0842$; EI-MS, $m / z$ (\%) (rel. int.) $298\left[\mathrm{M}^{+}\right.$(100), 297 (17), 283 (10), 269 (3), 166 (22), 132 (25), 117 (10).

4'-Hydroxy-7,4'-dimethoxyisoflavone (6): White crystals, HR-EI-MS, $m / z 298.0845\left[\mathrm{M}^{+}\right.$, Calcd for $\mathrm{C}_{17} \mathrm{H}_{14} \mathrm{O}_{5}, 298.0842$; EI-MS, $\mathrm{m} / z$ (\%) (rel int.) $298[\mathrm{M}]^{+}(100), 297(25), 283(10), 269(3), 180(5), 118(20)$.

7-Acetoxy-5,4'-dimethoxyisoflavone (5Ac): White crystals, EI-MS, $\mathrm{m} / \mathrm{z}$ (\%) (rel. int.) $340[\mathrm{M}]^{+}(100),{ }^{1} \mathrm{H}-\mathrm{NMR}\left(\mathrm{CDCl}_{3}\right)$ see Table 1.

4'-Acetoxy-7,4'-dimethoxyisoflavone (6Ac): White crystals, EI-MS, $m / z$ (\%) (rel. int.) $340[\mathrm{M}]^{+}(100),{ }^{1} \mathrm{H}-\mathrm{NMR}\left(\mathrm{CDCl}_{3}\right)$ see Table 1 .

Administration of 6,7,4'-Trimethoxyisoflavone (2) and 7,4'-Dimethoxyisoflavone (3) Compounds $2(150 \mathrm{mg})$ and $\mathbf{3}(150 \mathrm{mg})$ were administrated in the same way. Extracts were mixed, the solvent was evaporated under reduced pressure, and $215.0 \mathrm{mg}$ and $210.0 \mathrm{mg}$ of extract was obtained. Recovery substrates $\mathbf{2}(148 \mathrm{mg})$ and $\mathbf{3}(148 \mathrm{mg})$ were isolated.

Acknowledgments This work was supported by "High-Tech Research Center" project for Private Universities: matching fund subsidy from MEXT (Ministry of Education, Culture, Sports, Science and Technology), 2004 2008 .

\section{References}

1) Okawa M., Kinjo J., Nohara T., Ono M., Biol. Pharm. Bull., 24, 1202-1205 (2001)

2) Naim M., Gestetner B., Zilkah S., Birk Y., Bondi A., J. Agric. Food Chem., 22, 806-810 (1974).

3) Price K. R., Fenwick G. R., Food Addit. Contam., 2, 73-106 (1985).

4) Chansakaow S., Ishikawa T., Sekine K., Okada M., Higuchi Y., Kubo M., Chaichantipyuth C., Planta Med., 66, 572-575 (2000).

5) Ishida H., Uesugi T., Hirai K., Toda T., Nukaya H.,Yokotsuka K., Tsuji K., Biol. Pharm. Bull., 21, 62-66 (1998).

6) Adlercreutz H., Honjo H., Higashi A., Fotsis T., Hamalainen E., Hasegawa T., Okada H., Am. J. Clin. Nutr., 54, 1093-1100 (1991).

7) Esaki H., Onozaki H., Morimitsu Y., Kawakishi S., Osawa T., Biosci. Biotechnol. Biochem., 62, 740-746 (1998).

8) Toda T., Uesugi T., Hirai K., Nukaya H., Tsuji K., Ishida H., Biol. Pharm. Bull., 22, 1193-1201 (1999).

9) Miyazawa M., Ohsawa M., J. Agric. Food Chem., 50, 4916-4918 (2002).

10) Miyazawa M., Ando H., Okuno Y., Araki H., J. Mol. Catal. B: Enzym., 27, 91-95 (2003).

11) Okuno Y., Miyazawa M., J. Nat. Prod., 67, 1876-1878 (2004). 
12) Miyazawa M., Miyamoto Y., Tetrahedron, 60, 3091-3096 (2004).

13) Okuno Y., Miyazawa M., Biol. Pharm. Bull., 27, 1289-1292 (2004).

14) Miyazawa M., Miyamoto Y., J. Mol. Catal. B: Enzym, 32, 123-130 (2005).

15) Talukdar A. C., Jain N., De S., Krishnamurty H. G., Phytochemistry, 53, 155-157 (2000)

16) Kubo M., Sakai M., Namba K., Naruto S., Chem. Pharm. Bull., 23,
2449-2451 (1975).

17) Miyazawa M., Takahashi K., Araki H., J. Chem. Technol. Biotechnol., 81, 674-678 (2006).

18) Sekizaki H., Yokosawa R., Chem. Pharm. Bull., 36, 4876- 4880 (1988).

19) Matsuda H., Morikawa T., Toguchida I., Yoshikawa M., Chem. Pharm. Bull., 50, 788-795 (2002). 